\title{
X-34 VEHICLE AERODYNAMIC CHARACTERISTICS
}

\author{
Gregory J. Brauckmann* \\ NASA Langley Research Center, Hampton, VA 23681-0001
}

\begin{abstract}
$\underline{\text { Abstract }}$
The X-34, being designed and built by the Orbital Sciences Corporation, is an unmanned sub-orbital vehicle designed to be used as a flying test bed to demonstrate key vehicle and operational technologies applicable to future reusable launch vehicles. The X-34 will be air-launched from an L-1011 carrier aircraft at approximately Mach 0.7 and 38,000 feet altitude, where an onboard engine will accelerate the vehicle to speeds above Mach 7 and altitudes to 250,000 feet. An unpowered entry will follow, including an autonomous landing. The X-34 will demonstrate the ability to fly through inclement weather, land horizontally at a designated site, and have a rapid turn-around capability. A series of wind tunnel tests on scaled models was conducted in foui facilities at the NASA Langley Research Center to determine the aerodynamic characteristics of the X-34. Analysis of these test results revealed that longitudinal trim could be achieved throughout the design trajectory. The maximum elevon deflection required to trim was only half of that available, leaving a margin for gust alleviation and aerodynamic coefficient uncertainty. Directional control can be achieved aerodynamically except at combined high Mach numbers and high angles of attack, where reaction control jets must be used. The X-34 landing speed, between 184 and 206 knots, is within the capabilities of the gear and tires, and the vehicle has sufficient rudder authority to control the required 30-knot crosswind.
\end{abstract}

\section{Nomenclature}

c mean aerodynamic chord

$C_{D} \quad$ drag-force coefficient

$\mathrm{C}_{\mathrm{Do}} \quad$ drag-force coefficient at $0^{\circ}$ angle of attack

$\mathrm{C}_{\mathrm{L}} \quad$ lift-force coefficient

$\mathrm{C}_{\mathrm{Lo}} \quad$ lift-force coefficient at $0^{\circ}$ angle of attack

$C_{1} \quad$ rolling-moment coefficient

\footnotetext{
*Aerospace Engineer, Aerothermodynamics Branch, Aero- and Gas-Dynamics Division, Senior Member AIAA.

Copyright $\odot 1998$ by the American Institute of Aeronautics and Astronautics, Inc. No copyright is asserted in the United States under Title 17, U.S.Code. The U.S. Government has a royalty. free license to exercise all rights under the copyright claimed herein for governmental purposes. All other rights are reserved by the copyright owner.
}

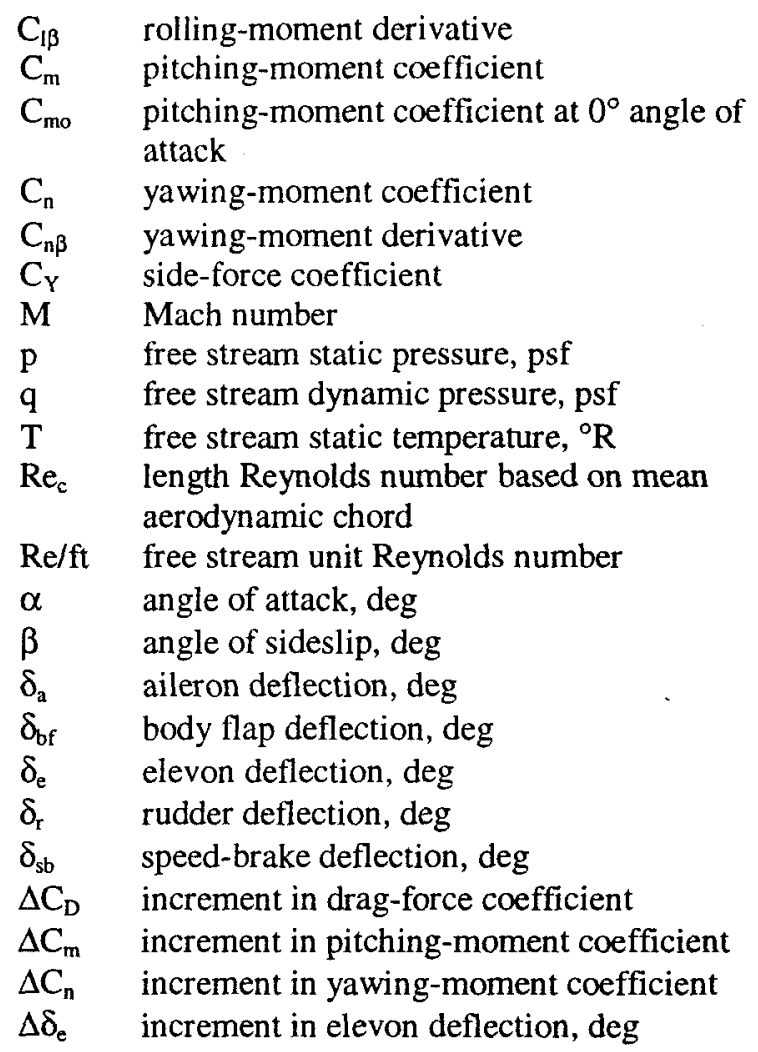

\section{Introduction}

The X-34, being designed and built by the Orbital Sciences Corporation, is an unmanned sub-orbital vehicle designed to be used as a flying test bed to demonstrate key vehicle and operational technologies applicable to future reusable launch vehicles (RLV). The X-34 will be air-launched from an L-1011 carrier aircraft at approximately Mach 0.7 and 38,000 feet altitude. An onboard engine will accelerate the vehicle to speeds above Mach 7 and altitudes to 250,000 feet. An unpowered entry will follow, including an autonomous landing. The $\mathrm{X}-34$ will demonstrate the ability to fly through inclement weather, land horizontally at a designated site, and have rapid turnaround capability. Key technologies used in the construction or operation are composite primary and secondary airframe structures, advanced thermal protection systems (TPS) and materials, a flush air data system, and automated vehicle checkout.

The X-34 vehicle is approximately $54 \mathrm{ft}$. long with a wingspan of 28 feet. Vehicle dry weight is 
approximately 18,000 pounds. The aerodynamic control surfaces are inboard and outboard elevons, a body flap, an all-moving vertical tail, and a tailmounted speed brake.

The present X-34 program started in the summer of 1996. Previously OSC had teamed with Rockwell International on an earlier, larger vehicle, and the current design is based on this work. A short series of wind tunnel tests (1 subsonic, I transonic, and 1 hypersonic) was conducted in the fall of 1996 in order to assess the current design. These experimental data were used to refine engineering code predictions that formed the initial aerodynamic database. At this time the vehicle aerodynamic characteristics were determined to be acceptable, in that controlled flight could be achieved. Due to the fast-paced nature of the program (first flight was to have been in 1998) no further optimization of the aerolines was made and the vehicle outer mold lines were thus frozen in December 1996. A set of 'benchmark' wind tunnel tests followed, the results of which are discussed in this paper, to define the final aerodynamic characteristics of the vehicle. The new tests would form the basis for the flight aerodynamic database, replacing the earlier wind tunnel data and engineering code predictions as each new test was completed.

The nominal trajectory of the $\mathrm{X}-34$ is presented in Fig. 1. The angle of attack, Mach number, and Reynolds number are shown as functions of time, for both the ascent and descent trajectories. On ascent, the X-34 maintains a low angle of attack, around $5^{\circ}$, except in the initial transonic phase just after drop. Here the vehicle pitches to a higher angle of attack $\left(\sim 13^{\circ}\right)$ to rapidly establish a steep flight path angle to pull the vehicle out of the lower atmosphere as quickly as possible. On descent, the angle of attack is initially maintained at $25^{\circ}$ and then is progressively lowered. For this trajectory, the maximum Mach number is 7.2 at an altitude of 250,000 feet. The Reynolds number shown in Fig. 1c is based on free stream conditions and the mean aerodynamic chord. Wind tunnel data were not obtained at flight values of Reynolds numbers except at high supersonic and hypersonic Mach numbers.

The wind tunnel test matrix for the aerodynamic database development is shown in Table 1 . The minimum and maximum control surface deflections tested were $-15^{\circ}$ to $+20^{\circ}$ for the body flap, $-30^{\circ}$ to $+20^{\circ}$ for the elevons, $-5^{\circ}$ to $+30^{\circ}$ for the tail/rudder, and $0^{\circ}$ to $77^{\circ}$. for the speed brake. Only limited data for coupled controls were obtained. The effect of landing gear on the aerodynamic performance was examined at Mach 0.25 . Ground effects will be determined in a future test that will also re-examine the effects due to the landing gear.

\section{$\underline{\text { Models }}$}

The majority of the data presented (all except the Mach 0.25 data) were obtained with models representing the latest outer-mold-line (OML) geometry. This geometry was obtained from OSC in IGES format, and was designated X1001215. Two models were built to these aerolines, a .018 scale and a .033 scale. A third model, of .018 scale, was fabricated prior to this and thus represented the OML of an earlier geometry. The major difference in the aerolines was the inclusion of the TPS blanket geometry on the later models. This TPS resulted in aft-facing ramps on the upper surface of the wing (approximately 10\% back from the leading edge), and also aft-facing ramps in the nose region. The ramps were due to different thicknesses of thermal blankets.

A partial engine bell was fabricated and tested for each model. This bell had the lower portion removed to prevent fouling with the sting. The bell was placed at a $15^{\circ}$ inclination to the waterline, which represented the full upward deflection of the nozzle. Landing gear and doors were fabricated for the initial .018 model.

All the models were made of aluminum and/or stainless steel, and control surface deflections were achieved by use of individual brackets. The rudder deflection was set by use of a locating pin. The speed brakes were attached to the aft section of the tail. For the initial .018 model, the speed brakes were of a wedge type, while for the later models, a split speed brake design was used. A 3-view sketch of the vehicle is given in Fig. 2. The reference areas and lengths are given below.

\begin{tabular}{lccc}
\hline Dimension & Full scale & $\mathbf{. 0 3 3}$ scale & $\mathbf{. 0 1 8}$ scale \\
& & & \\
Wing area (ft $\left.{ }^{2}\right)$ & 357.5 & 0.3972 & 0.1199 \\
Wing chord (in) & 174.5 & 5.8167 & 3.1960 \\
Wing span (in) & 332.5 & 11.0833 & 6.0897 \\
Length (in) & 646.9 & 21.6540 & 11.8978
\end{tabular}

\section{Facilities}

Four facilities were used to obtain the aerodynamic data presented in this paper. A brief description of each is given. Nominal flow conditions are presented in Table 2.

\section{LaRC Low Turbulence Pressure Tunnel}

The Langley Low Turbulence Pressure Tunnel ${ }^{1}$ (LTPT) is a single-return, closed-throat pressure tunnel with a 3- by 7.5-ft. test section. Mach number can be varied from 0.15 to 0.3 . The tunnel can be pressurized 
from 1 to 10 atmospheres to vary the unit Reynolds number. Low turbulence levels are achieved by using a large contraction ratio and a number of fine-wire smallmesh screens in the settling chamber. A pitch/roll mechanism is used to set model attitude. Mach number is determined from measured values of total and static pressures.

\section{LaRC 16ft Transonic Wind Tunnel}

The Langley 16-foot Transonic Tunnel ${ }^{2}$ is a closed circuit, single return, continuous flow atmospheric tunnel with a slotted wall test section. The test medium is air with an air exchange for cooling. The normal testing range is Mach numbers from 0.2 to 1.3 and angles of attack up to $25^{\circ}$. Speeds up to Mach 1.05 are obtained with the tunnel main drive fans; speeds above this are obtained with a combination of main drive fans and test-section plenum suction. The slotted octagonal test section nominally measures 15.5 feet across the flats. The usable test section length is 22 feet for speeds up to Mach 1.0 and 8 feet for speeds above Mach 1.0. Mach number is determined from measured values of total and static pressures.

\section{LaRC Unitary Plan Wind Tunnel}

The Langley Unitary Plan Wind Tunnel ${ }^{3}$ is a closedcircuit pressure tunnel with two 4 - by 7 - $\mathrm{ft}$. test sections. The major elements of the facility are the $100,000 \mathrm{hp}$. drive system, a dry air supply and evacuating system, a cooling system, and the interconnecting ducting to provide the proper air flow to either of the two test sections. The tunnel circuit is designed to operate at pressures from near vacuum to 10 atmospheres. The low-Mach number test section covers the range from 1.46 to 2.86 , and the high-Mach number test section covers the range from 2.3 to 4.63 . The nozzle walls are asymmetric, and the lower wall of the nozzle moves longitudinally to provide the necessary variation in area ratio. The model/sting support mechanism is capable of an angle of attack range from $-12^{\circ}$ to $22^{\circ}$ (with higher angles obtainable with the use of dogleg stings), sideslip of $+/-14^{\circ}$, and roll continuous through $310^{\circ}$. Mach number is determined from the position of the nozzle block. Calibrations are periodically performed to verify the initial calibration.

\section{LaRC 20-Inch Mach 6 Air Tunnel}

The Langley 20-Inch Mach 6 Air Tunnel ${ }^{4}$ is a hypersonic blow down facility that uses heated, dried, and filtered air as the test gas. Typical operating conditions for the tunnel are stagnation pressures from 30 to 500 psia, stagnation temperatures from 750 to $1000^{\circ} \mathrm{R}$, and free stream unit Reynolds numbers from 0.5 to 8 million per foot. A two-dimensional, contoured nozzle is used to provide nominal free stream Mach numbers from 5.8 to 6.1 . The test section is 20.5 by 20 inches; the nozzle throat is 0.4 by 20.5 inches. A bottom-mounted model injection system can insert models from a sheltered position to the tunnel centerline in less than 0.5 seconds. Run times up to 15 minutes are possible with this facility; current test run times were on the order of two minutes. The Mach number was determined from previous facility calibrations, and measured values of pitot pressure were compared to these calibrations to determine if any significant changes had occurred.

\section{Instrumentation and Test Procedures}

The aerodynamic forces and moments were measured with a six-component strain gage balance. Three different balances were used to manage the load range occurring for all facilities. The models were sting mounted through the base in all facilities. The balance was water-cooled to minimize heating effects in the 20 Inch Mach 6 Tunnel. The data were acquired in a pitch pause manner in all facilities. All tests measured the cavity pressure by use of pressure tubes run along the sting into the model cavity. Base pressures were measured by use of tubes that ran alongside the sting into the base region in the LTPT and 20-Inch Mach 6 Tunnel, and by actual orifices on the base for the other facilities. All axial data are corrected for chamber pressure adjusted to the average base pressure. Corrections for weight tares, balance interactions, and sting deflections are also included. The moment reference center is $64.65 \%$ of the model length, unless otherwise stated. Boundary layer transition trips (carborundum grit strips) were used to provide turbulent flow in all facilities except the 20-Inch Mach 6 Tunnel and UPWT test section 2. A typical tunnel installation (UPWT-2) is shown in Fig. 3a. Details of the base area including the split speed brake design are shown in Fig. 3b.

A rigorous uncertainty analysis has not been performed as yet for the wind tunnel data. An estimate is made by assuming an uncertainty of $0.5 \%$ of the balance full scale loads. The quoted balance accuracies are better, but this conservative approach can allow for uncertainties in other parameters such as model attitude and flow uniformity. The estimated uncertainties are presented in Table 3 . In addition, data repeatability within each test (series of runs in a given facility) was examined by determining the standard deviation of the error from all repeat points. Data repeatability was generally well within the balance uncertainty estimates. Excursions outside these limits occurred in the transonic regime between Mach 0.6 and Mach 1.05 for normal force and rolling moment. The uncertainty 
estimates do not include any bias error to be included in the tinal flight database from such sources as protuberance drag, drag due to the blanket roughness, and non-flight Reynolds number.

\section{$\underline{\text { Results and Discussion }}$}

The longitudinal characteristics of the $\mathrm{X}-34$ are shown in Figs. $4 \mathrm{a}-4 \mathrm{~d}$, plotted against Mach number. There is a slight increase in $\mathrm{C}_{\mathrm{Lo}}$ with Mach number for the subsonic Mach numbers up to Mach 0.9 , then a sharp drop, which recovers at Mach 0.98 , and a steady decrease throughout the supersonic Mach numbers. The initial increase in $C_{L}$ is attributed to compressibility effects. $C_{D o}$ experiences the onset of the transonic drag rise above Mach 0.8. The drag then decreases for Mach numbers above 1.25. While drag is not of primary importance on descent for vehicles of this type, the acceleration of the vehicle will be affected, limiting the final altitude and Mach number achieved. $C_{m o}$ is negative for all Mach numbers and this is an indication, which will be borne out later, that negative (up) deflections of the control surfaces will be needed to trim the vehicle longitudinally. There is an increase in nose-down moment as the transonic regime is encountered, then less nose-down moment as the supersonic and hypersonic Mach numbers are reached. The affect of the break in lift (near Mach 0.95) can be seen here again as a break in the pitching moment. The longitudinal stability of the vehicle is shown in Fig. 4d. The data have been adjusted to the flight angle of attack and center of gravity (c.g.) locations. Negative values of $\partial \mathrm{C}_{\mathrm{m}} / \partial \mathrm{C}_{\mathrm{L}}$ indicate positive stability. As can be seen, the vehicle is stable for transonic and low supersonic Mach numbers, but is unstable at other Mach numbers.

The lateral-directional characteristics $C_{1 \beta}$ and $C_{n} \beta$ are shown in Figs. $5 a$ and $5 b$. The vehicle is stable in roll (negative values of $C_{1 \beta}$ ) for subsonic Mach numbers (and more so at higher angles of attack, where the wing dihedral is more effective), but is less stable for transonic Mach numbers and above. Indeed, the vehicle is unstable or neutrally stable for angles of attack less than $12^{\circ}$ for Mach numbers greater than 1.2. The X-34 is stable directionally (positive values of $C_{n \beta}$ ) for subsonic Mach numbers and lower angles of attack (typically $<16^{\circ}$ ). There is a general decrease in stability as both Mach number and angle of attack increase, primarily due to the tail being shielded by the body. The vehicle is unstable for all angles of attack for Mach numbers greater than 1.6.

The effect of the partial engine bell is presented in Figs. $6 a$ and $6 b$. For the $15^{\circ}$ deflection (relative to the waterline) tested, the bell extended above the fuselage upper surface. The effect on drag is presented as a percentage of the total vehicle drag. The effect is only appreciable below Mach 1; otherwise it is less than $3 \%$. The largest effect (16\% at Mach 0.25$)$ occurs, as expected, at an angle of attack of $0^{\circ}$ and rapidly decreases to less than $5 \%$ for angles of attack greater than $12^{\circ}$. The bell causes a maximum nose-up increment in pitch of .02 , which is equivalent to about $1^{\circ}-2^{\circ}$ of elevon deflection. The pitch increment becomes negligible above Mach 2 .

The elevon effectiveness is shown in Figs. 7a-7c for several angles of attack. The increments in $C_{m}$ shown are those between successive deflection angles, i.e. between $0^{\circ}$ and $-10^{\circ}$, between $-10^{\circ}$ and $-20^{\circ}$, and between $-20^{\circ}$ and $-30^{\circ}$. In general, for any of the angles of attack shown the effectiveness increases with Mach number up to Mach 1, then decreases for supersonic Mach numbers. At $0^{\circ}$ angle of attack (Fig. 7a) there is a dramatic decrease in effectiveness for the largest deflection for most Mach numbers less than 1.6, probably due to leeside separation caused by the flap. For high subsonic Mach numbers there is also a decrease for the intermediate deflection value. As the Mach number increases above 3, the largest deflection has the greatest effect for $\alpha=0^{\circ}$, possibly due to increased pressure on the aft portion of the wing, behind the vehicle c.g. As the angle of attack increases, there continues to be a decrease in effectiveness for larger deflections at subsonic Mach numbers, as well as at supersonic Mach numbers.

The speed brakes are intended as an energy management device, but will also play an important role in providing longitudinal trim. The speed brakes are not intended to be used above Mach 3 due to heating concerns. The increments in $C_{D}$ and $C_{m}$ with Mach number are shown in Fig. 8. There is a general decrease in drag with Mach number and with angle of attack. The pitching-moment increment is shown in Fig. 8b. There is no monotonic trend with Mach number, with the maximum increment occurring for Mach 1.05. This implies that the speed brake is also affecting the flow on the fuselage upper surface, and possibly the wing or other areas. The non-linearity exhibited for angles of attack greater than $12^{\circ}$ is likely due to vortices impinging on the tail.

The rudder effectiveness $\left(\Delta C_{n}\right)$ is shown in Fig. 9 for a $10^{\circ}$-rudder deflection. Rudder effectiveness for the subsonic and transonic Mach numbers is generally constant with angle of attack. At supersonic Mach numbers, and more so for hypersonic Mach numbers, the rudder effectiveness decreases with angle of attack, and is ineffective above $20^{\circ}$ angle of attack for the highest Mach number. This will necessitate the use of reaction control jets for portions of the trajectory. The rudder is more effective as Mach number increases up 
to Mach 1.05 , then the effectiveness decreases with Mach number.

The effectiveness of the rudder and speed brakes are mutually affected. Figs. $10 \mathrm{a}-10 \mathrm{c}$ present the increment in $C_{n}$ for the rudder deflected $-5^{\circ}$ with and without a $62^{\circ}$ speed brake deployed. Rudder effectiveness is degraded for subsonic Mach numbers but is actually more effective with the speed brake deployed for supersonic Mach numbers. This trend holds true throughout the angle of attack range. This can be understood by assuming that subsonically, the deflected brake separates the flow on the tail, causing it to generate less lift. Supersonically, the increased pressure due to the "wedge" shock increases the tail effectiveness.

The aileron effectiveness is shown in Figs. 11a-11f. The aileron effectiveness decreases as Mach number increases, similar to the elevon effectiveness. For subsonic and low supersonic Mach numbers, the effectiveness is fairly symmetrical between positive and negative deflections. Hypersonically, positive deflections are much more powerful (greater than twice the rolling moment). Subsonically, negative deflections produce a favorable yawing moment, while positive deflections produce almost no accompanying yawing moment. At low supersonic Mach numbers, positive deflections produce an adverse yaw, of a magnitude near that for negative deflections, which still have a favorable yaw. Hypersonically, both deflections produce adverse yawing moments, with positive deflections again producing much larger moments.

The overall trim capability of the vehicle is shown next by presenting the control surface time histories throughout the trajectory. A computer program was used that simply calculates the deflections needed to achieve trim, and was not a true flight simulation. Of course, full 6-degree-of-freedom simulations will be performed before first flight. A hierarchical use of control surfaces was assumed as follows: thrust vectoring, body flap deflection, speed brake deflection, and finally elevon deflection. Figs. $12 \mathrm{a}$ and $12 \mathrm{~b}$ present the time histories if speed brake deflections are not allowed. As seen, the body flap is deflected to its maximum up position $\left(-15^{\circ}\right)$ for most of the trajectory, and the maximum elevon deflection is $-15^{\circ}$. This is only half the maximum elevon deflection available, leaving a margin for gust alleviation and aerodynamic coefficient uncertainty. The time histories are shown in Figs. $12 \mathrm{c}$ and $12 \mathrm{~d}$ with the speed brake activated. The use of the speed brake does not affect the maximum elevon or body flap deflections required, just their duration, since the speed brake is only used below Mach 3.

The subsonic landing trim capability is shown in Fig. 13 for several configurations. These data are presented for the landing c.g. of $65.6 \%$ of body length. The effect of deploying the landing gear is seen as a small nose-down pitch increment, which vanishes for angles of attack above $16^{\circ}$. The landing gear also increases the drag significantly, as seen in Fig. $13 b$. The vehicle is longitudinally unstable, and negative deflections are required to trim, which will decrease the available lift. The angle of attack at landing will be around $8^{\circ}-10^{\circ}$. With the body flap deflected up $10^{\circ}$ and the gear deployed, the vehicle can then trim with a $\mathrm{C}_{\mathrm{L}}$ between 0.35 and 0.44 . These values correspond to landing speeds between 184 and 206 knots, which are within the capability of the tires and landing gear systems. Deploying the landing gear affects the elevon effectiveness, as seen in Fig. 14. The elevon effectiveness is reduced by approximately $10 \%$.

The landing gear also affects the lateral-directional characteristics of the vehicle as seen in Fig. $15 . \mathrm{Cn}_{\beta}$ is seen to change from positive stability (for angles of attack less than $14^{\circ}$ ) to negative stability when the gear is deployed. This can be attributed to the nose gear, and its far forward location relative to the center of gravity. In addition, the nose gear causes a yawing moment even at $0^{\circ}$ sideslip, as seen in Fig. 16. This moment is not present when only the main gear is deployed. It is assumed that the nose gear pressurizes the nose gear door, of which there is only one, situated to the left of the vehicle centerline.

The rudder effectiveness is presented in Fig. 17. It is nearly constant with angle of attack, with only a small decrease in effectiveness as the deflection magnitude increases. The vehicle can easily control a sideslip of $8.6^{\circ}$ (corresponding to a crosswind of 30 knots at the landing speed), requiring only a $2.5^{\circ}$ rudder deflection.

\section{Conclusions}

A series of wind tunnel tests on scaled models was conducted in four facilities at the NASA Langley Research Center to determine the aerodynamic characteristics of the X-34. Analysis of these test results revealed that longitudinal trim could be achieved throughout the design trajectory. The maximum elevon deflection required to trim was only half of that available, leaving a margin for gust alleviation and aerodynamic coefficient uncertainty. Directional control can be achieved aerodynamically except at combined high Mach numbers and high angles of attack, where reaction control jets must be used. The X-34 landing speed, between 184 and 206 knots, is within the capabilities of the gear and tires, and the vehicle has sufficient rudder authority to control the required 30-knot crosswind. 
Elevon elfectiveness decreased rapidly for deflections larger than $-20^{\circ}$. The rudder and speed brake interacted aerodynamically, decreasing rudder effectiveness for subsonic Mach numbers, but increasing it for supersonic Mach numbers.

\section{References}

'McGhee, R. J., Beasley, W. D., and Foster, J. M.: "Recent Modifications and Calibration of the Langley
Low-Turbulence Pressure Tunnel," NASA TP-2328, 1984.

${ }^{2}$ Capone, F. J., Bangert, L. S., Asbury, S. C., Mills, C. T., and Bare, E. A.: "The NASA Langley 16-Foot Transonic Tunnel," NASA TP-3521, September 1995.

${ }^{3}$ Jackson, C. M., Corlett, W. A., and Monta, W. J.: "Description and Calibration of the Langley Unitary Plan Wind Tunnel," NASA TP-1905, November 1981.

${ }^{4}$ Micol, J.M.: Hypersonic Aerodynamic/Aerothermodynamic Testing Capabilities at Langley Research Center: Aerothermodynamic Facilities Complex," AIAA paper 95-2107, 1995.

Table 1. X-34 Test Matrix

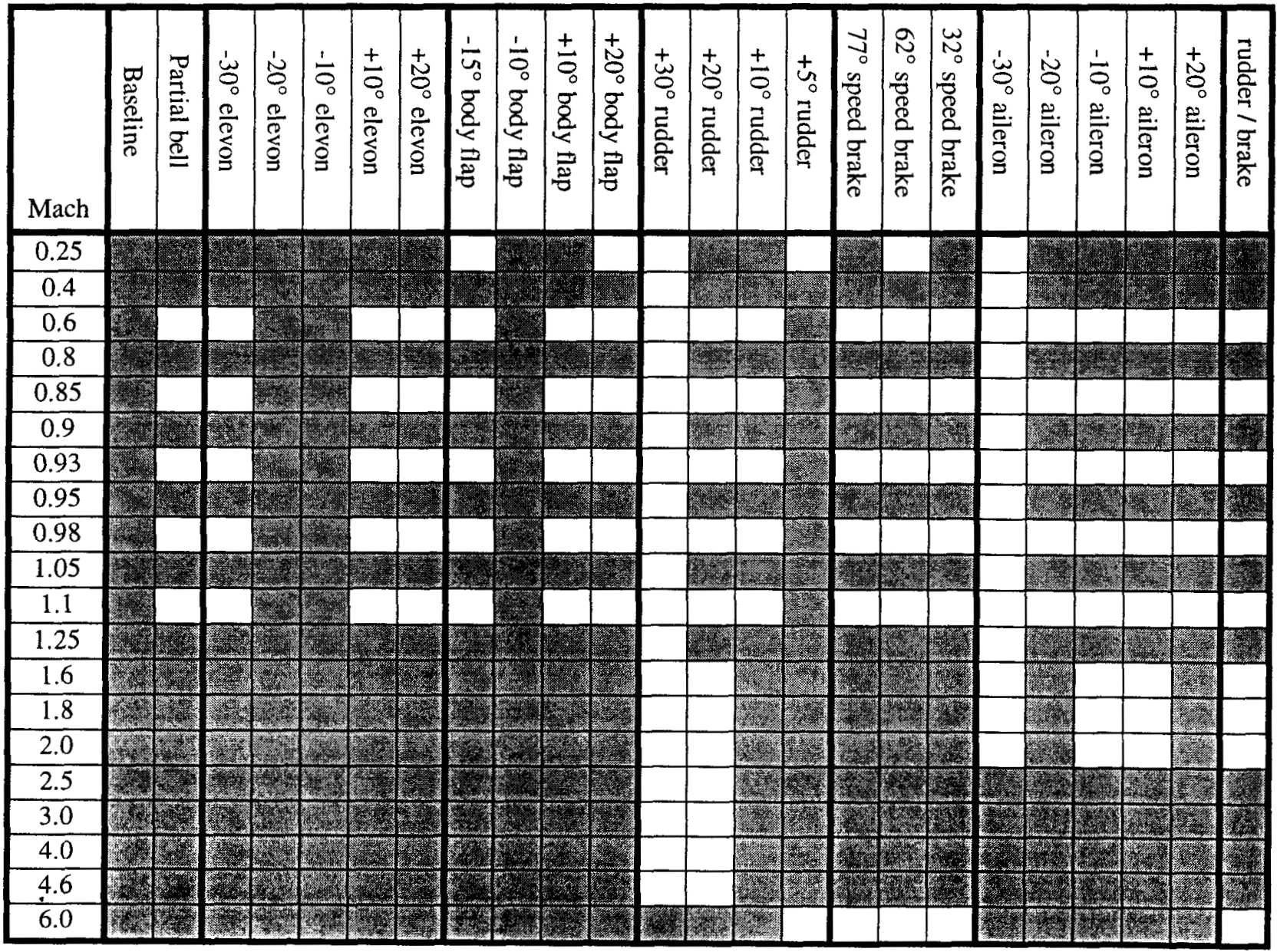


Table 2. Nominal Flow Conditions

\begin{tabular}{lllllll} 
Facility & Mach & $\mathbf{q}, \mathbf{p s f}$ & $\mathbf{p}, \mathbf{p s f}$ & $\mathbf{T},{ }^{\circ} \mathbf{R}$ & $\mathbf{R e} / \mathbf{f t}$ & $\begin{array}{c}\mathbf{R e}_{\mathbf{c}} \\
\text { LTPT }\end{array}$ \\
16ft TT & 0.25 & 300 & 6945 & 533 & $5.6 \times 10^{6}$ & $1.5 \times 106$ \\
& 0.4 & 212 & 1895 & 567 & 2.3 & 1.1 \\
& 0.6 & 418 & 1659 & 546 & 3.1 & 1.5 \\
& 0.8 & 622 & 1388 & 519 & 3.7 & 1.8 \\
& 0.85 & 667 & 1319 & 511 & 3.8 & 1.8 \\
& 0.9 & 709 & 1251 & 503 & 3.9 & 1.9 \\
& 0.925 & 729 & 1217 & 500 & 4.0 & 1.9 \\
& 0.95 & 748 & 1184 & 496 & 4.0 & 1.9 \\
& 0.98 & 769 & 1144 & 491 & 4.0 & 1.9 \\
UPWT-1 & 1.05 & 813 & 1053 & 479 & 4.1 & 2.0 \\
& 1.1 & 839 & 991 & 471 & 4.1 & 2.0 \\
UPWT-2 & 1.25 & 893 & 817 & 446 & 4.2 & 2.0 \\
& 1.6 & 910 & 507 & 387 & 4.0 & 2.0 \\
& 1.8 & 911 & 402 & 355 & 4.0 & 2.0 \\
& 2.0 & 897 & 320 & 325 & 4.0 & 2.0 \\
20-Inch Mach 6 6 & 2.5 & 870 & 199 & 271 & 4.0 & 2.0 \\
& 3.0 & 760 & 121 & 218 & 4.0 & 2.0 \\
& 4.0 & 546 & 49 & 145 & 4.0 & 2.0 \\
& 4.6 & 436 & 29 & 117 & 4.0 & 2.0 \\
& 6.0 & 138 & 5 & 108 & 1.0 & 0.5 \\
& 6.0 & 575 & 11 & 111 & 2.0 & 1.0 \\
\hline \hline
\end{tabular}

Table 3. Estimated uncertainties

\begin{tabular}{|c|c|c|c|c|c|c|c|}
\hline $\begin{array}{l}\text { Facility } \\
\text { LTPT }\end{array}$ & $\begin{array}{c}\text { Mach } \\
0.25\end{array}$ & $\begin{array}{c}\mathbf{C}_{\mathbf{N}} \\
.0216\end{array}$ & $\begin{array}{c}\mathbf{C}_{\mathrm{A}} \\
.0029\end{array}$ & $\begin{array}{l}\mathbf{C}_{\mathbf{m}} \\
.0092\end{array}$ & $\begin{array}{c}\mathbf{C}_{\mathbf{l}} \\
.0007\end{array}$ & $\begin{array}{c}\mathbf{C}_{\mathbf{n}} \\
0012\end{array}$ & $\begin{array}{c}\mathbf{C}_{\mathbf{Y}} \\
0072\end{array}$ \\
\hline \multirow[t]{11}{*}{$16 \mathrm{ft} \mathrm{TT}$} & 0.4 & .0042 & .0051 & .0179 & .0017 & .0040 & 0179 \\
\hline & 0.6 & .0021 & .0026 & . 0091 & .0009 & .0020 & .0091 \\
\hline & 0.8 & .0014 & .0017 & .0061 & .0006 & .0014 & 0061 \\
\hline & 0.85 & .0013 & .0016 & .0057 & .0006 & .0013 & 0057 \\
\hline & 0.9 & .0013 & .0015 & .0054 & .0005 & .0012 & .0053 \\
\hline & 0.925 & .0012 & .0015 & .0052 & .0005 & .0012 & .0052 \\
\hline & 0.95 & .0012 & .0014 & .0051 & .0005 & .0011 & .0051 \\
\hline & 0.98 & .0012 & .0014 & .0049 & .0005 & .0011 & .0049 \\
\hline & 1.05 & .0011 & .0013 & .0047 & .0005 & .0011 & .0047 \\
\hline & 1.1 & .0011 & .0013 & .0045 & .0004 & .0010 & .0045 \\
\hline & 1.25 & .0010 & .0012 & .0043 & .0004 & .0010 & .0042 \\
\hline \multirow[t]{3}{*}{ UPWT-1 } & 1.6 & .0083 & .0008 & .0043 & .0005 & .0008 & .0028 \\
\hline & 1.8 & .0083 & .0008 & .0043 & .0005 & .0008 & .0028 \\
\hline & 2.0 & .0084 & .0008 & .0044 & .0005 & .0008 & .0028 \\
\hline UPWT-2 & 2.5 & .0087 & .0009 & .0045 & .0005 & .0008 & .0029 \\
\hline \multirow[t]{3}{*}{ 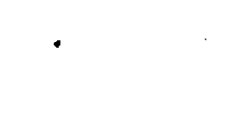 } & 3.0 & .0100 & .0010 & .0051 & .0006 & .0009 & .0033 \\
\hline & 4.0 & .0139 & .0014 & .0072 & .0008 & .0013 & .0046 \\
\hline & 4.6 & .0174 & .0017 & .0090 & .0011 & .0016 & .0058 \\
\hline 20-Inch Mach 6 & 6.0 & 0218 & .0054 & .0069 & .0005 & .0008 & .0045 \\
\hline
\end{tabular}




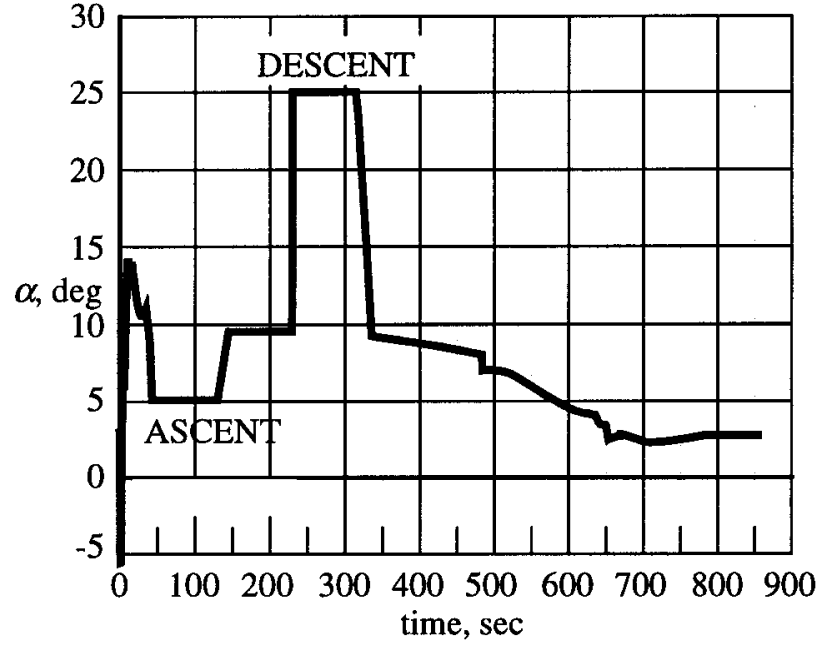

(a) angle of attack

Figure 1. X34 reference trajectory parameters

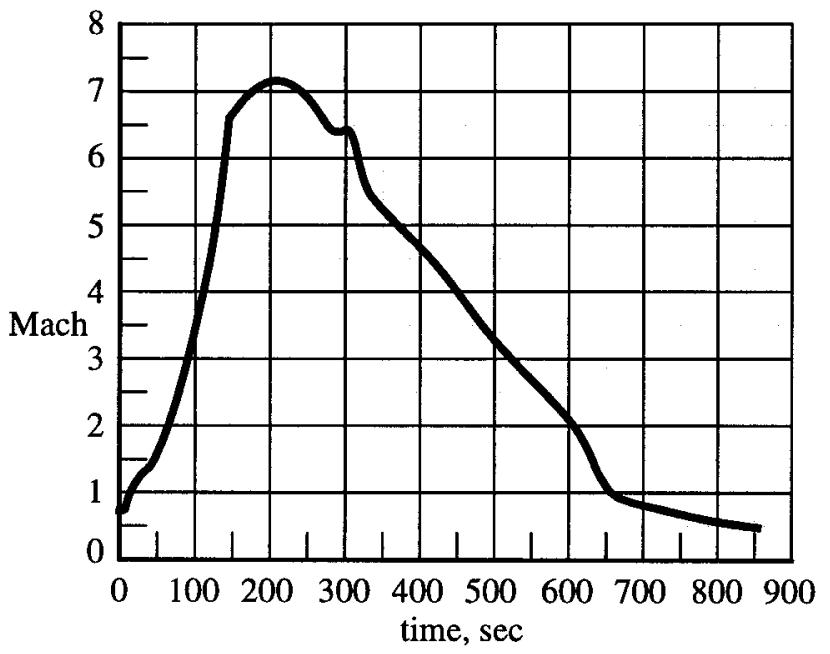

(b) Mach number

Figure 1. continued

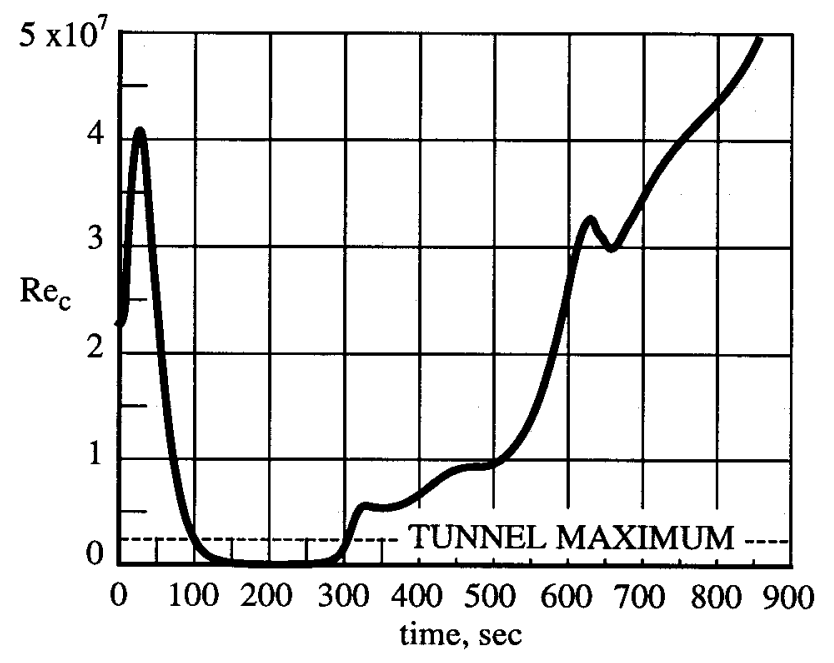

(c) chord Reynolds number

Figure 1. concluded

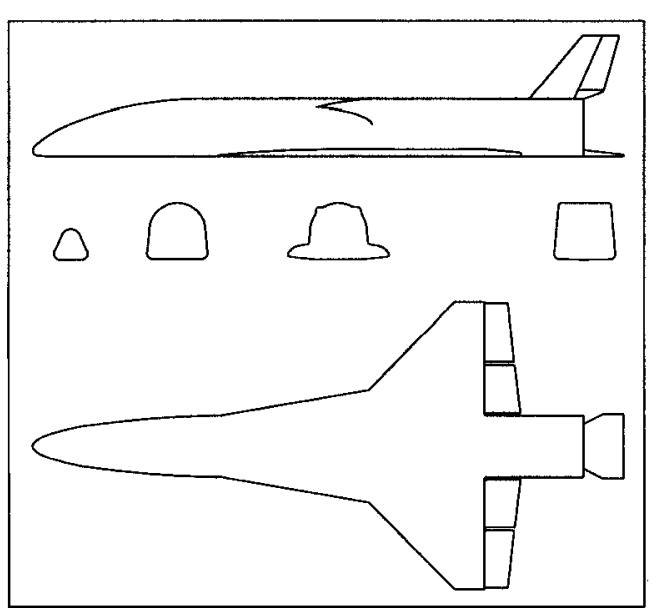

Figure 2. Sketch of X-34 geometry.

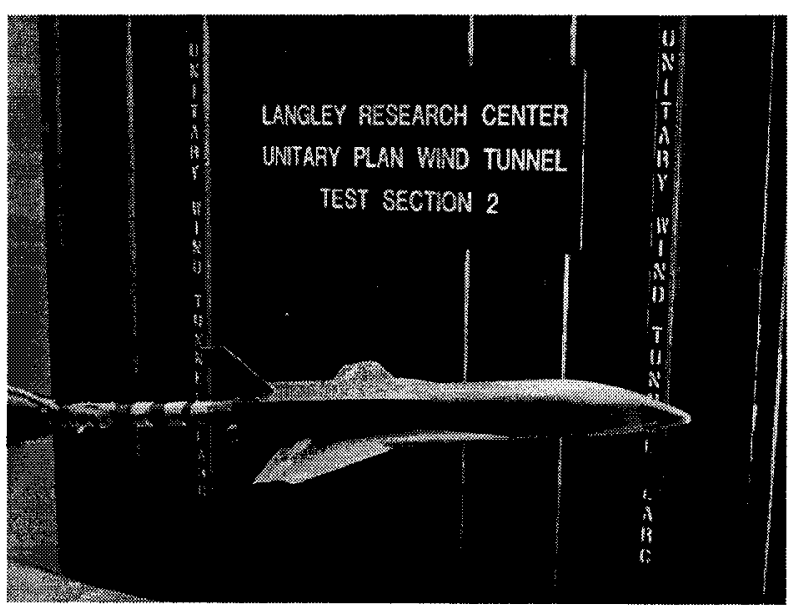

(a) overall view

Figure 3. Installation of .033 scale X-34 in Unitary Plan Wind Tunnel.

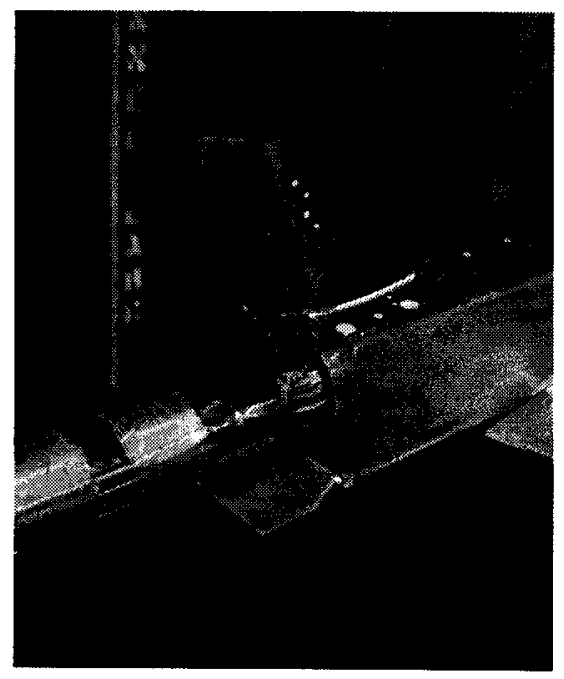

(b) detail of base area and speed brake Figure 3. concluded. 


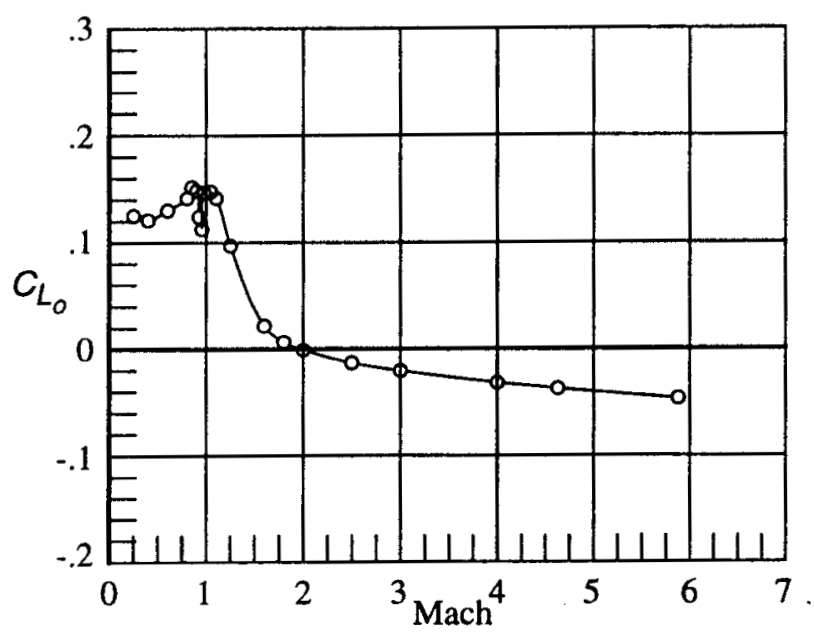

(a) $\mathrm{C}_{\mathrm{L}_{0}}$

Figure 4. Baseline longitudinal aerodynamic characteristics

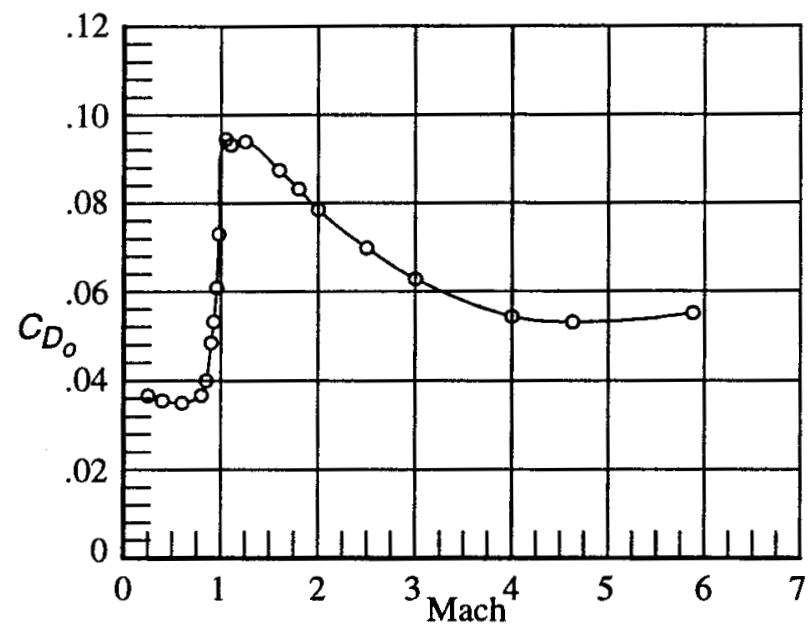

(b) $\mathrm{C}_{\mathrm{Do}}$

Figure 4. Continued

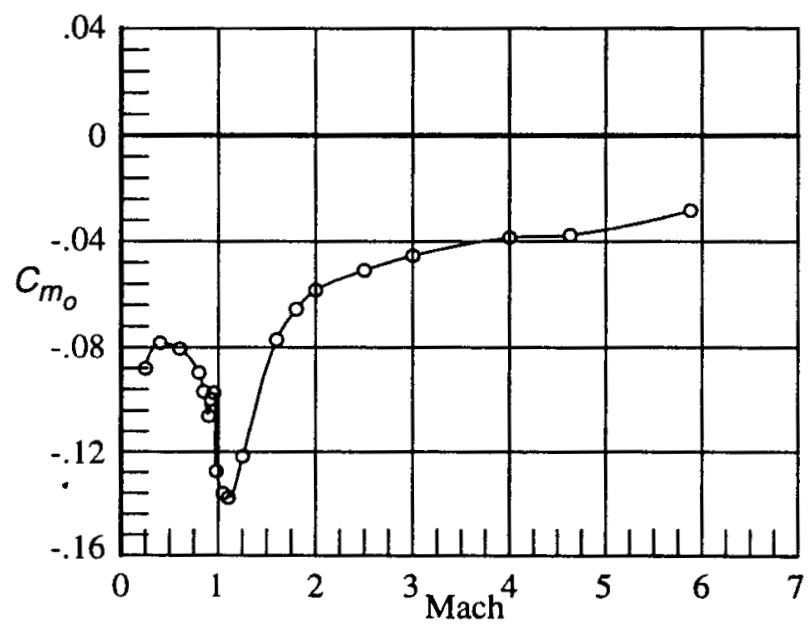

Figure 4. continued

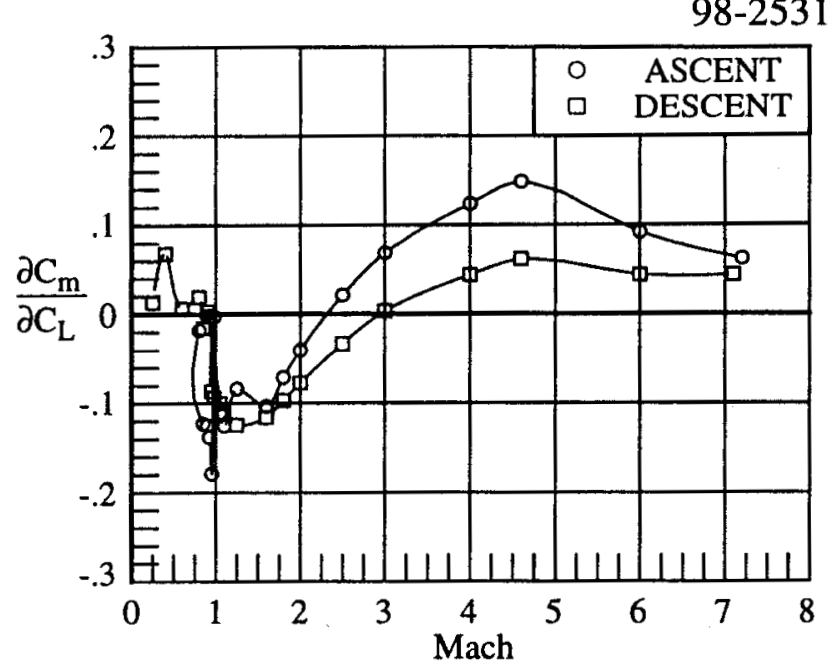

(d) $\partial C_{m} / \partial C_{L}$

Figure 4. concluded

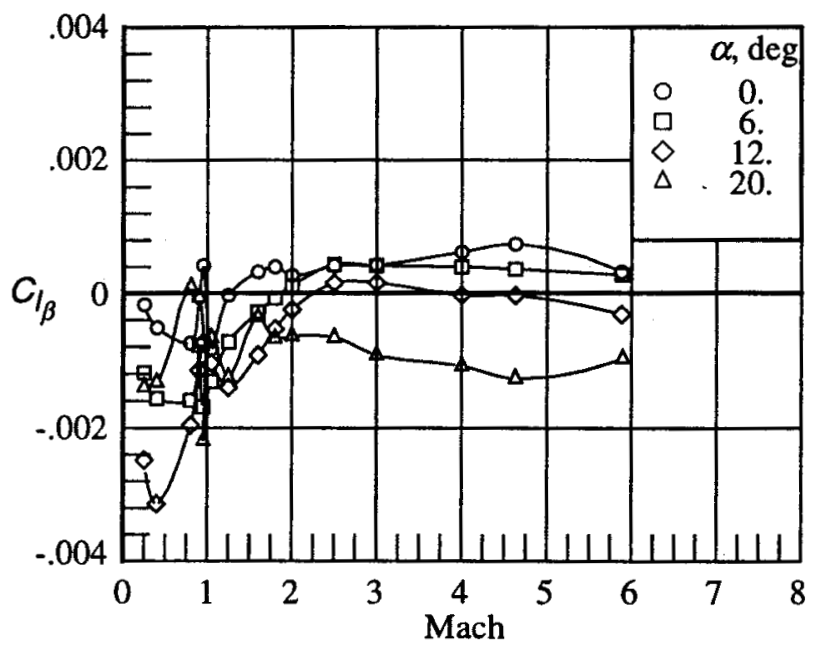

(a) $\mathrm{C}_{\mathrm{l}_{\beta}}$

Figure 5. Baseline lateral-directional characteristics

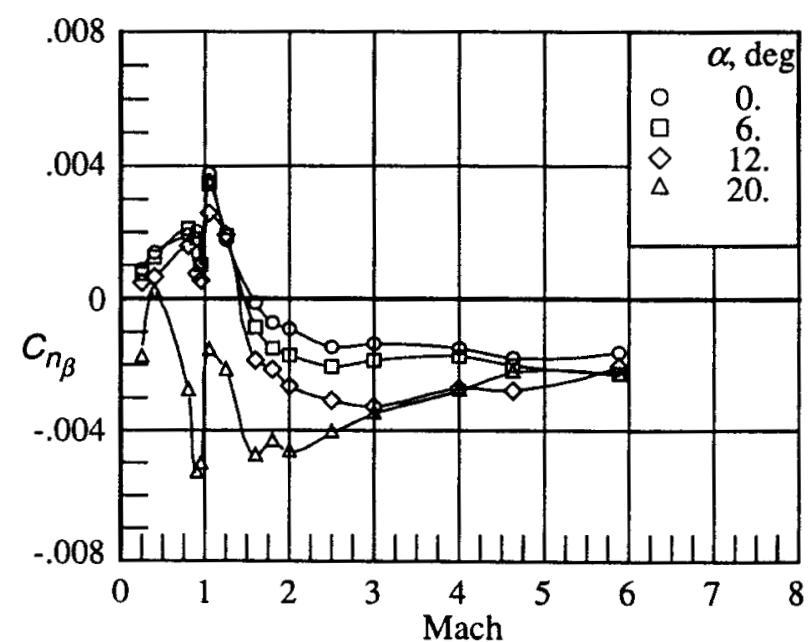

(b) $\mathrm{C}_{\mathrm{n}_{\beta}}$

Figure 5. concluded 
$98-2531$

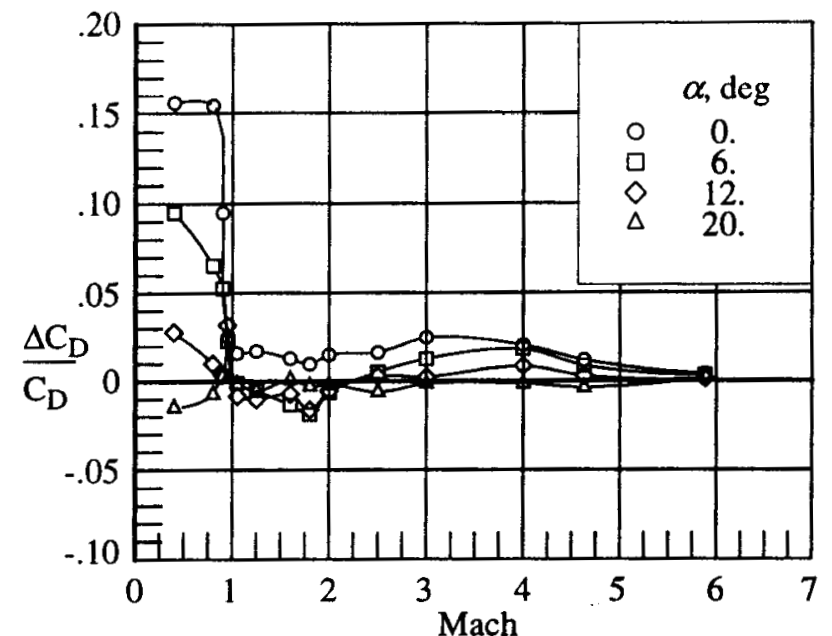

(a) $\Delta C_{D} / C_{D}$

Figure 6. Effect of engine bell

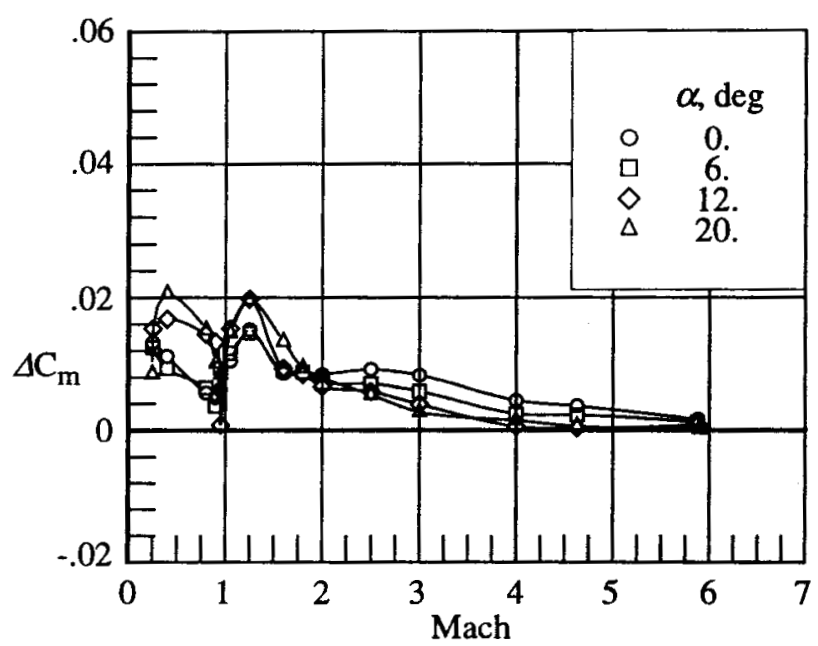

(b) $\Delta \mathrm{C}_{\mathrm{m}}$

Figure 6. concluded

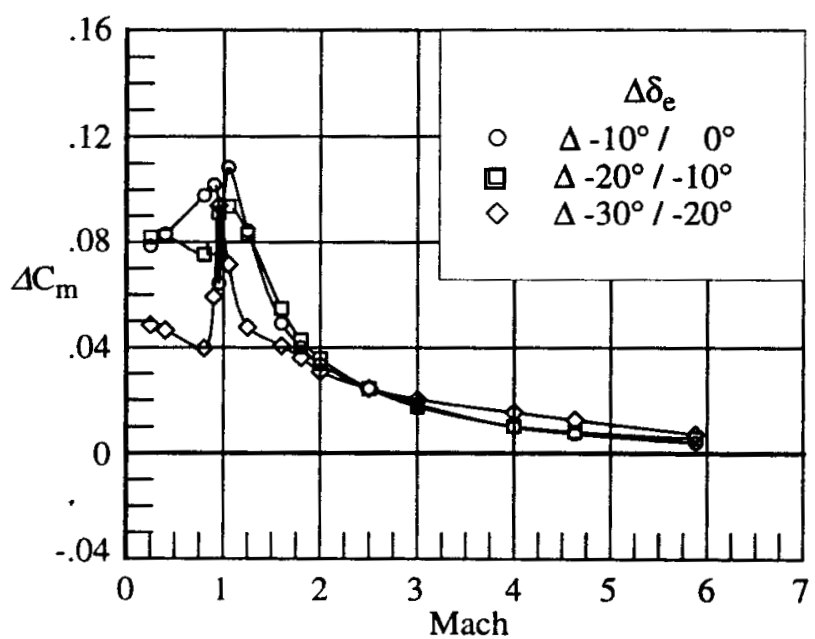

(a) $\alpha=0^{\circ}$

Figure 7. Effect of elevon deflection

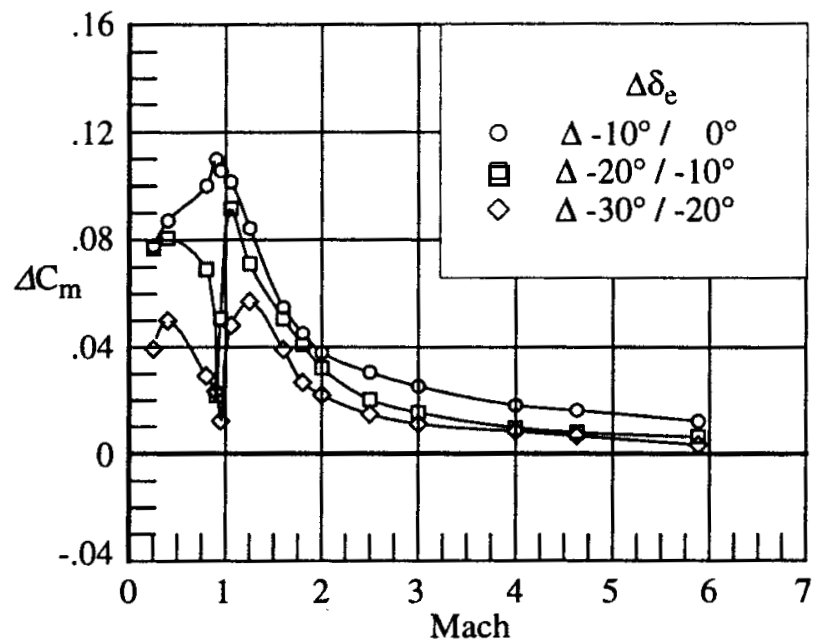

(b) $\alpha=12^{\circ}$

Figure 7. continued

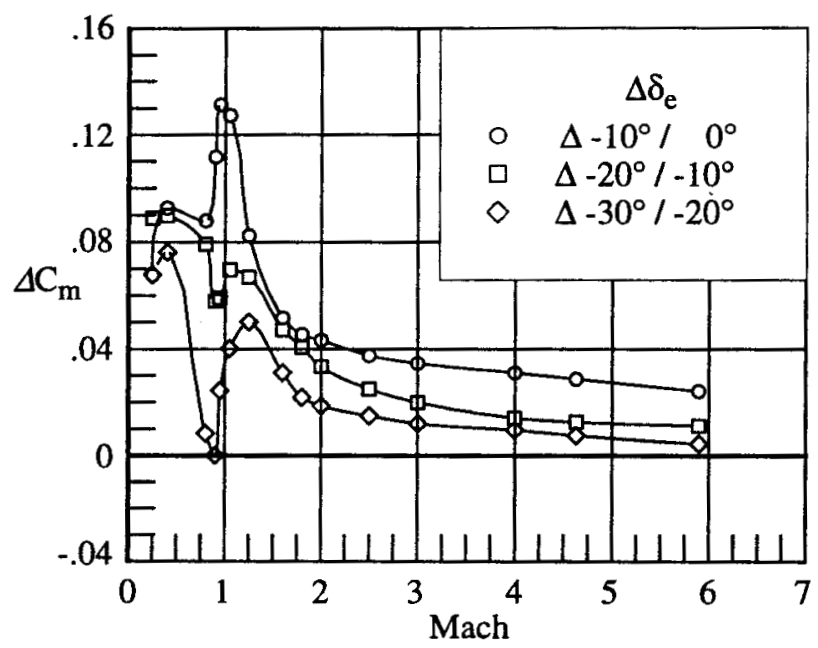

(c) $\alpha=20^{\circ}$

Figure 7. concluded

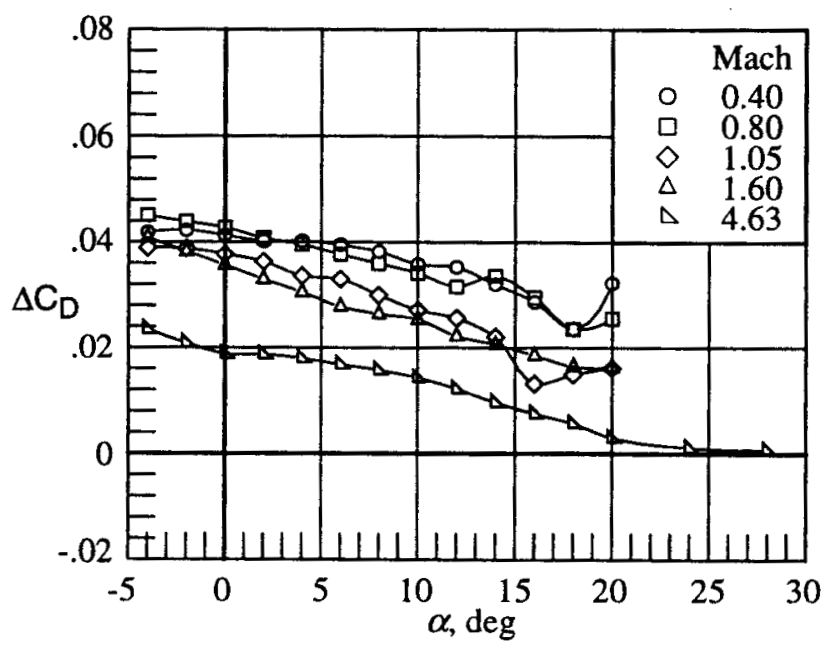

(a) $\Delta C_{D}$

Figure 8. Effect of speed brake deflection $\left(\delta_{\mathrm{sb}}=77^{\circ}\right)$ 


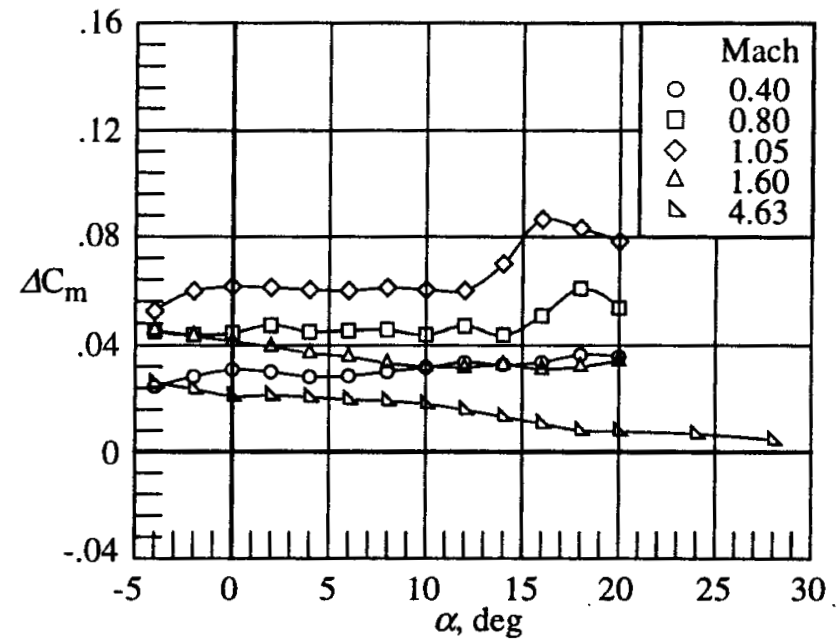

(b) $\Delta \mathrm{C}_{\mathrm{m}}$

Figure 8. concluded

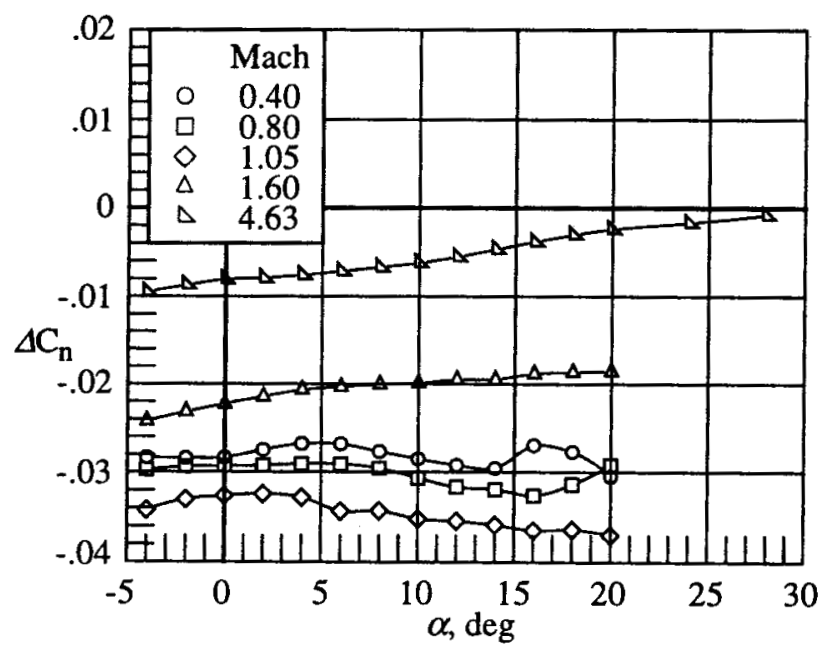

Figure 9. Effect of rudder deflection $\left(\delta_{\mathrm{r}}=10^{\circ}\right)$

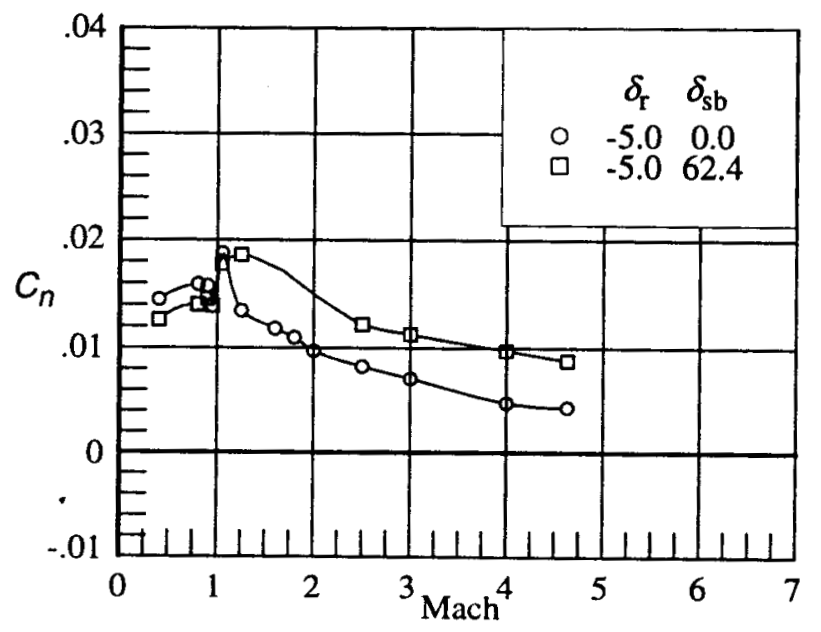

(a) $\alpha=0^{\circ}$

Figure 10. Effect of combined rudder/speed brake deflection

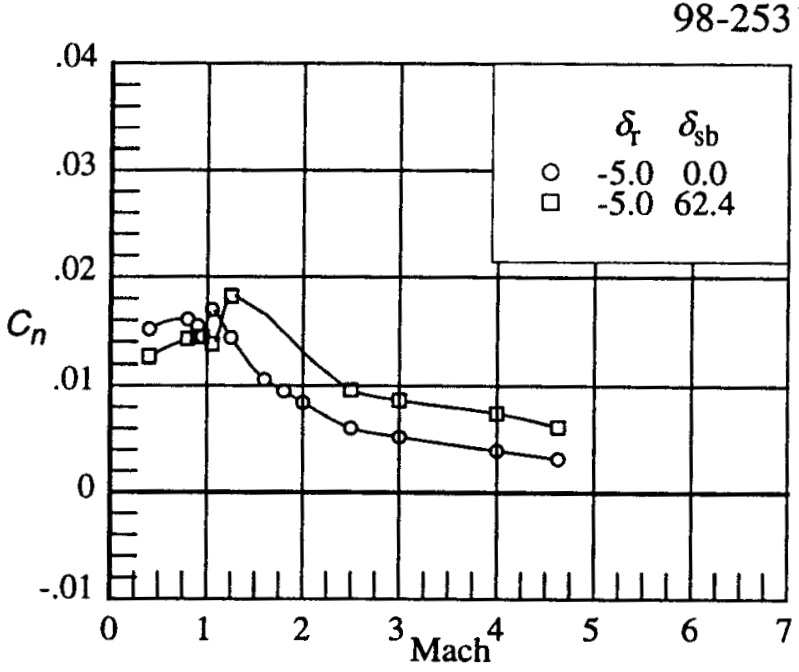

(b) $\alpha=12^{\circ}$

Figure 10. continued

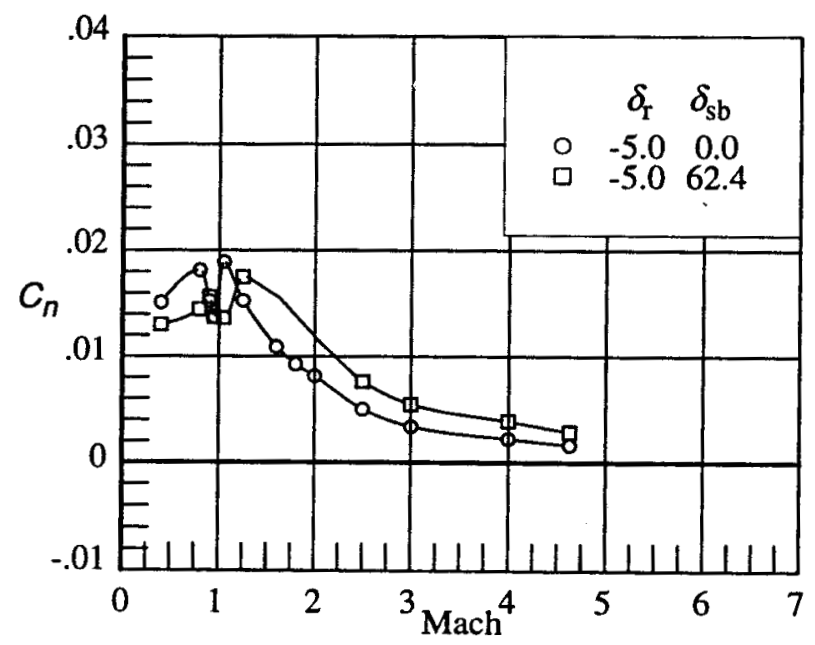

(c) $\alpha=20^{\circ}$

Figure 10. concluded

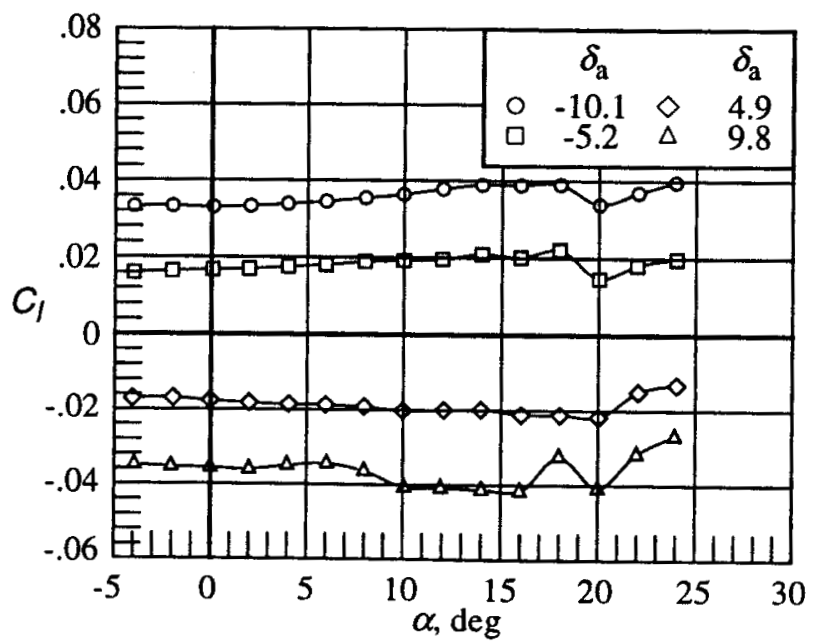

(a) $\mathrm{C}_{\mathrm{l}} \quad(\mathrm{Mach}=0.4)$

Figure 11. Effect of aileron deflection 
98-2531

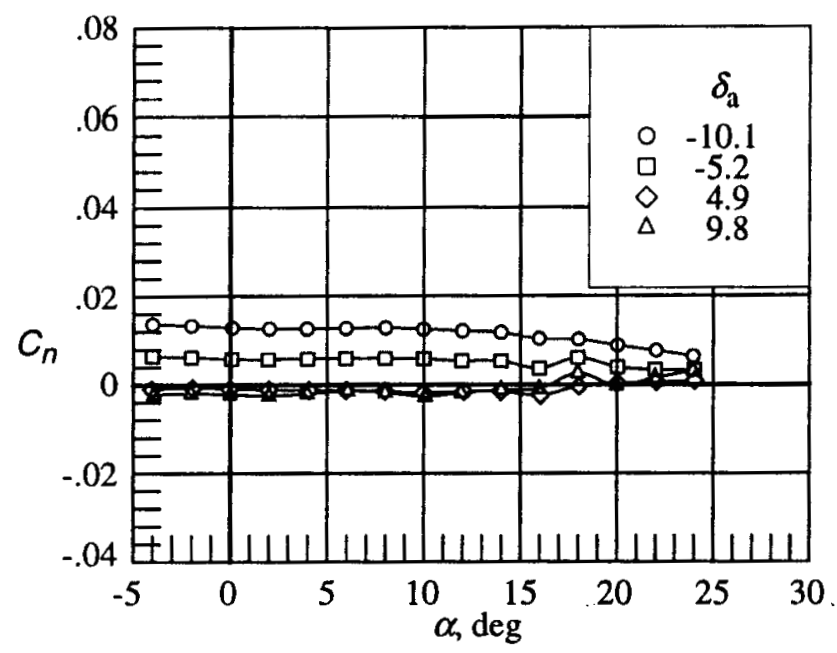

(b) $\mathrm{C}_{\mathrm{n}} \quad(\mathrm{Mach}=0.4)$

Figure 11. continued

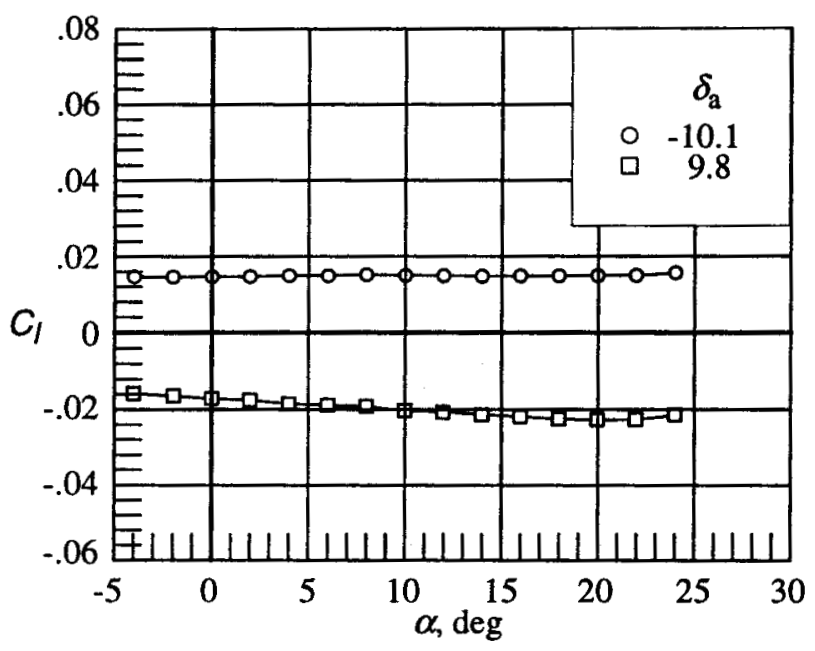

(c) $\mathrm{C}_{1} \quad(\mathrm{Mach}=1.6)$

Figure 11. continued

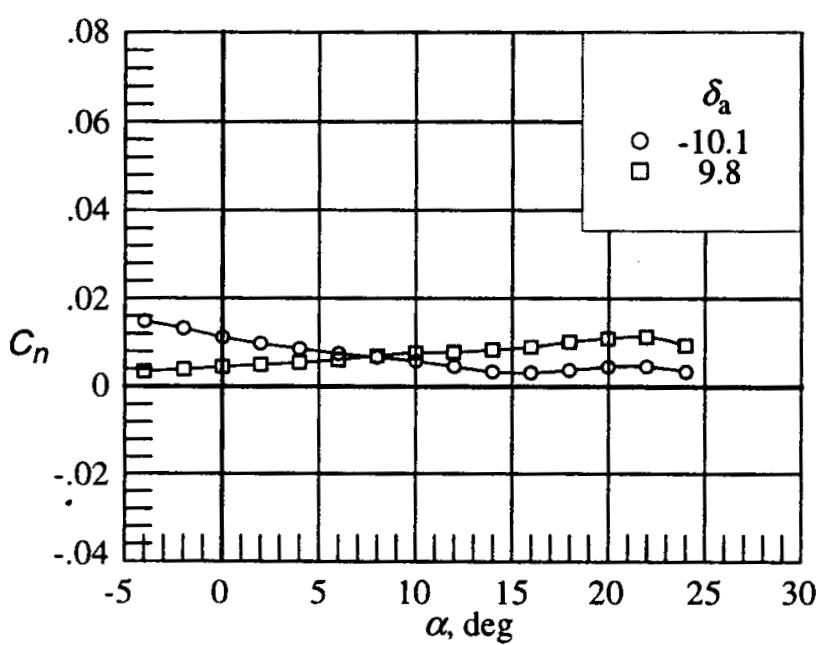

(d) $C_{n} \quad($ Mach $=1.6)$

Figure 11. continued

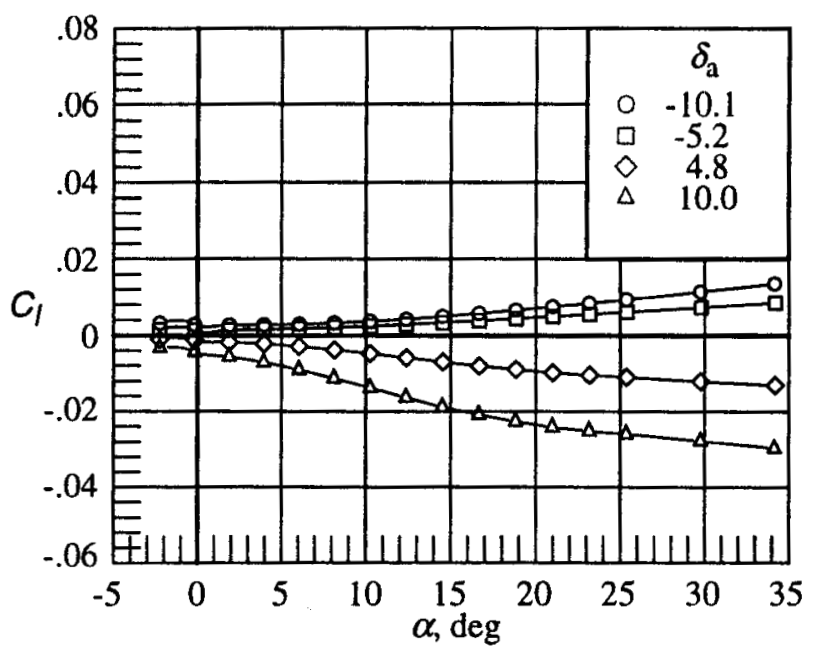

(e) $C_{1} \quad($ Mach $=6.0)$

Figure 11. continued

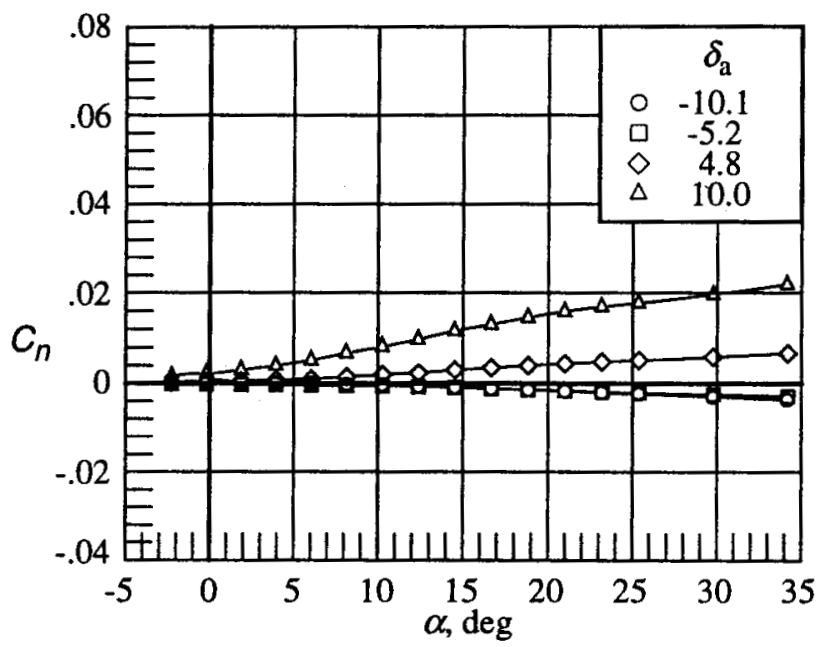

(f) $C_{n} \quad($ Mach $=6.0)$

Figure 11. concluded

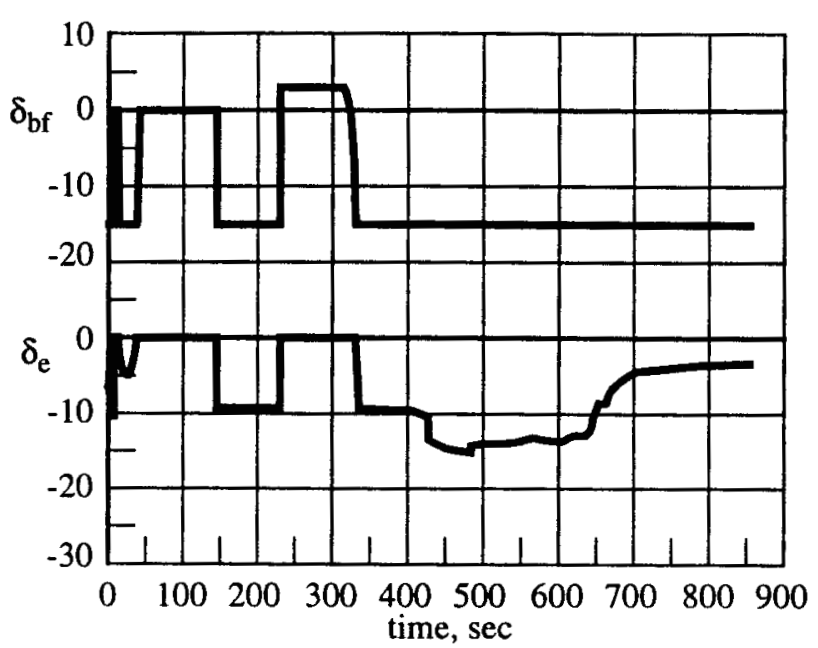

(a) no speed brake

Figure 12. Time history of control surface deflections 


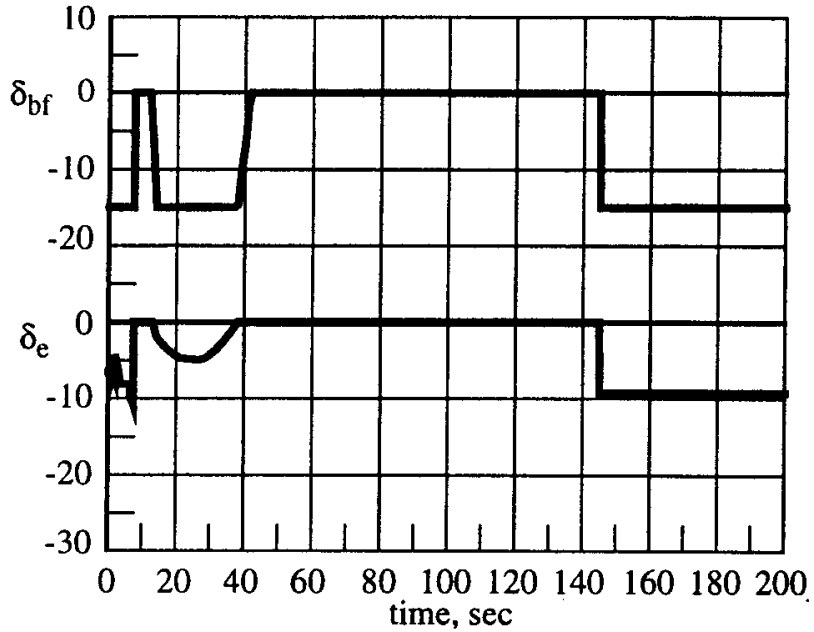

(b) no speed brake $(t<200 \mathrm{sec})$

Figure 12. continued

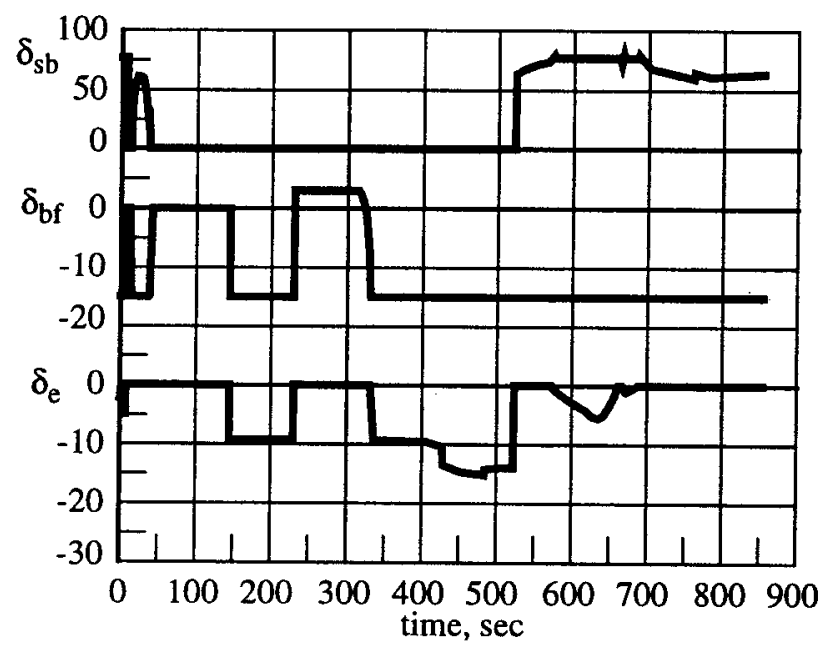

(c) with speed brake

Figure 12. continued

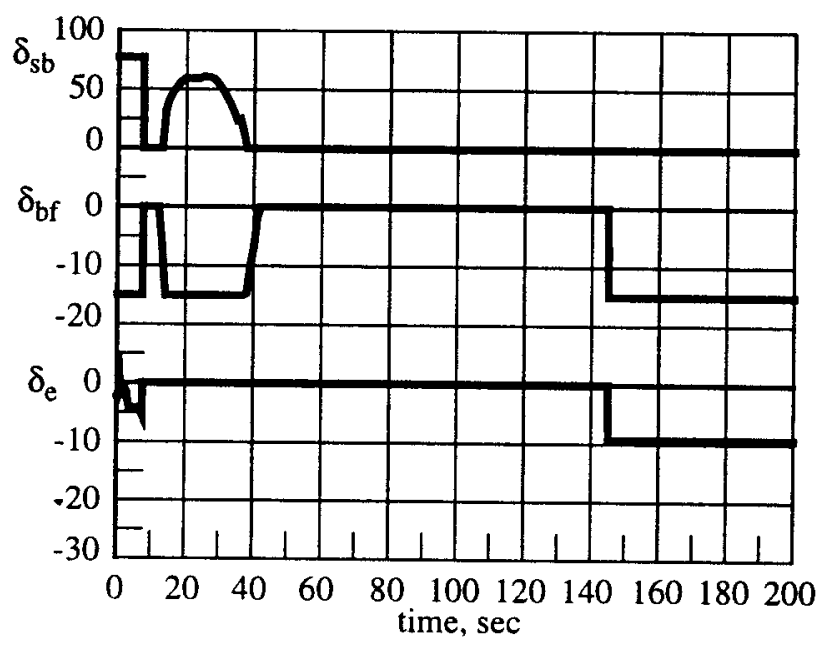

(d) with speed brake $(t<200 \mathrm{sec})$

Figure 12. concluded

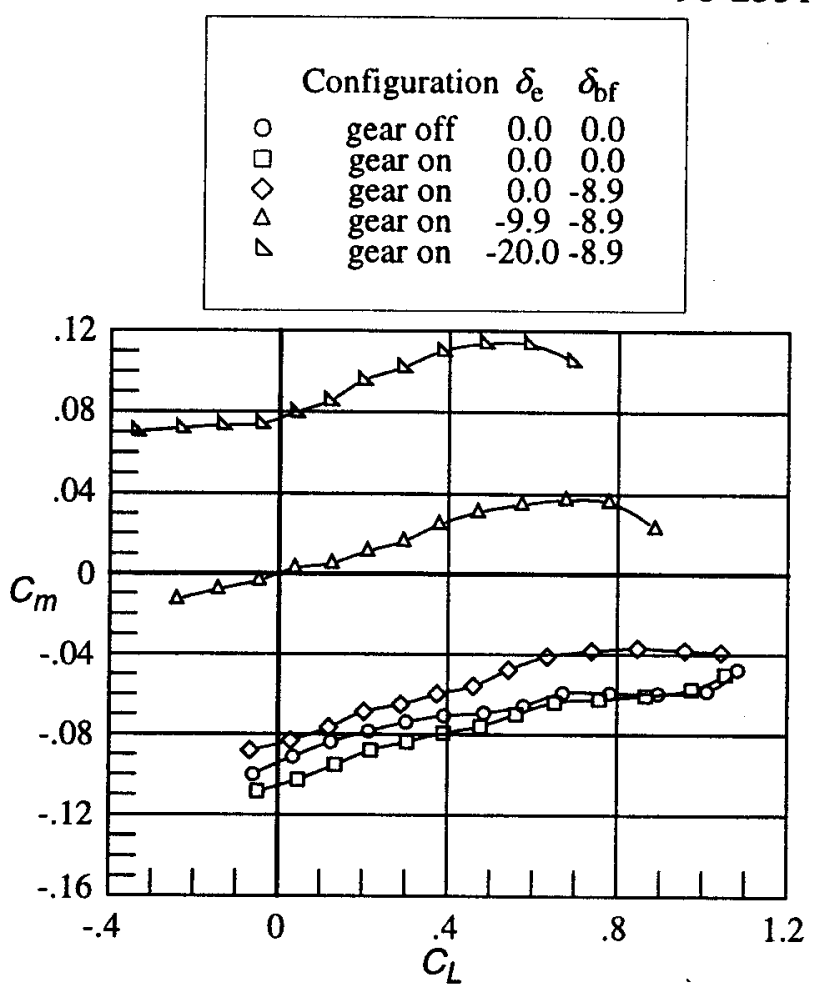

(a) $\mathrm{C}_{\mathrm{m}}$

Figure 13. Low speed trim capability
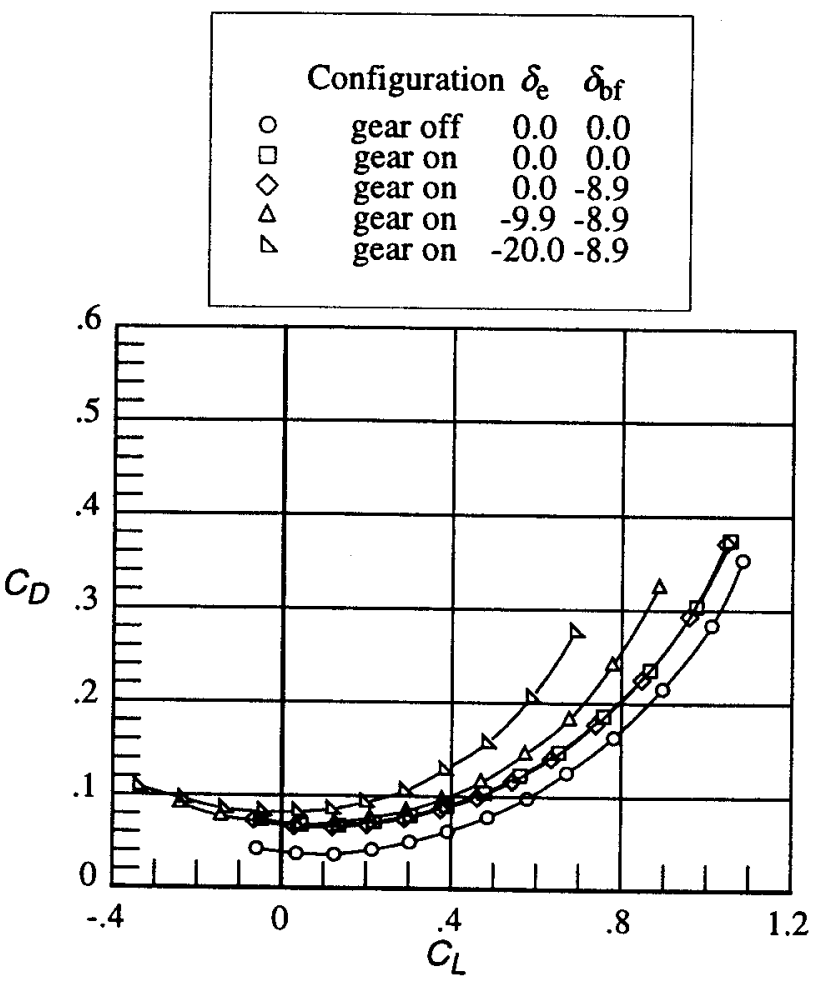

(b) $C_{D}$

Figure 13, concluded 


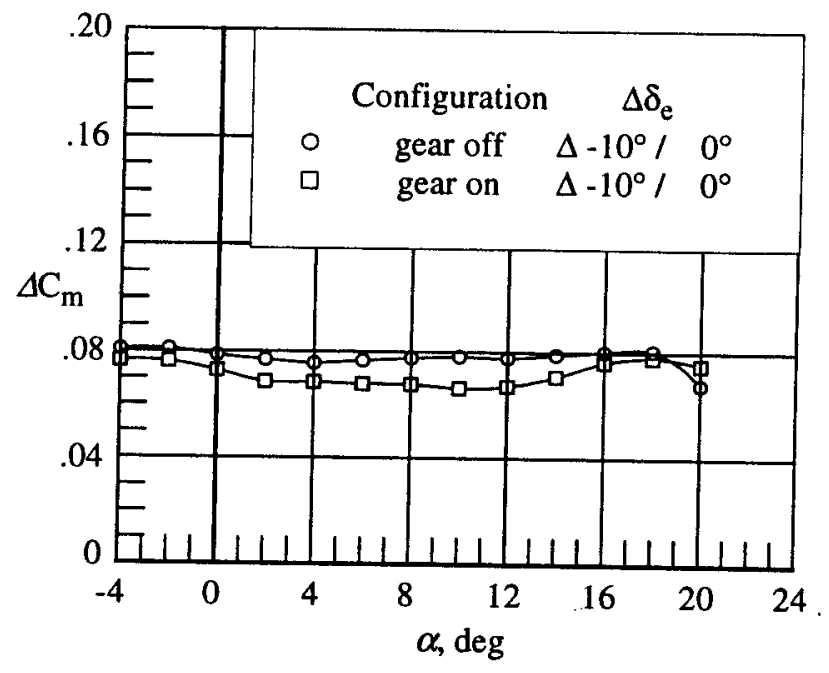

Figure 14. Effect of landing gear on elevon effectiveness

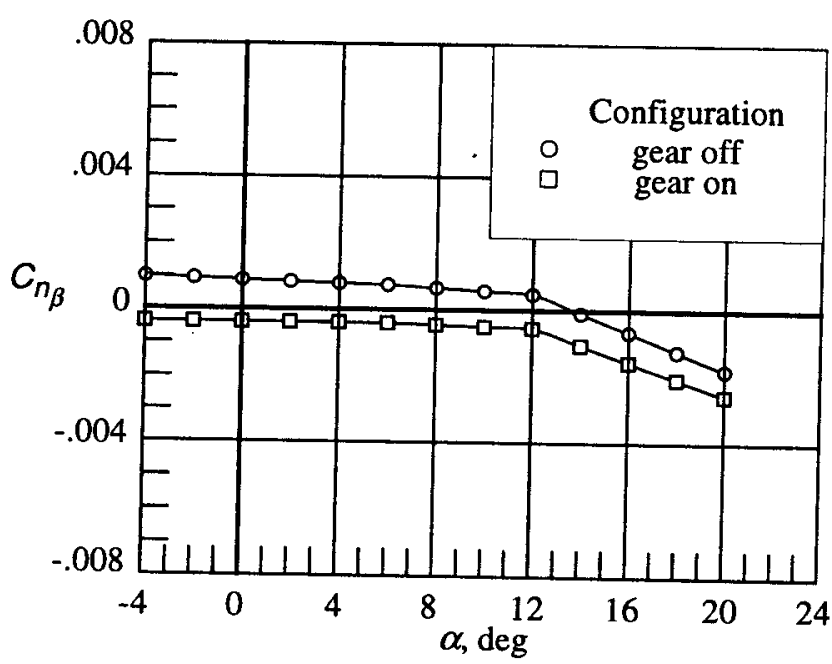

Figure 15. Effect of landing gear on low speed directional stability

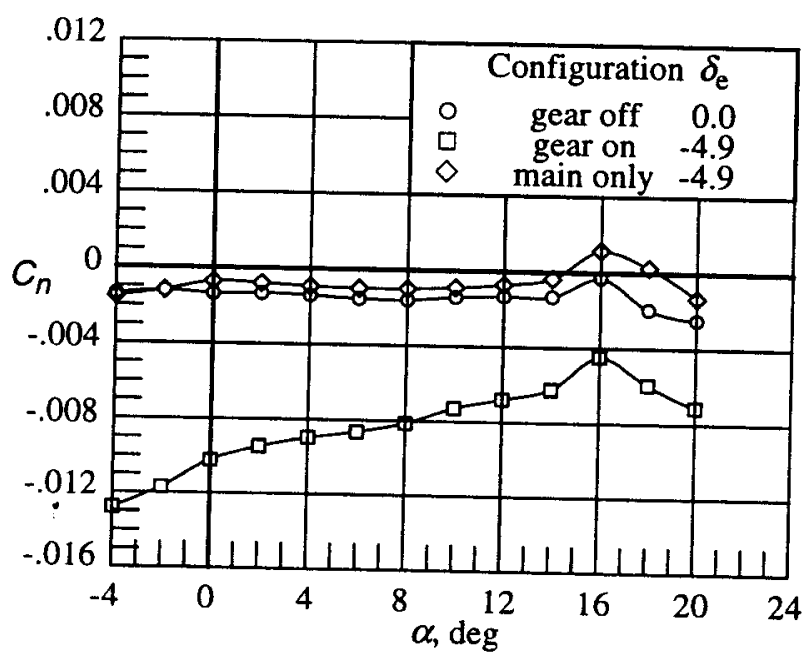

Figure 16. Effect of nose gear on low speed directional stability

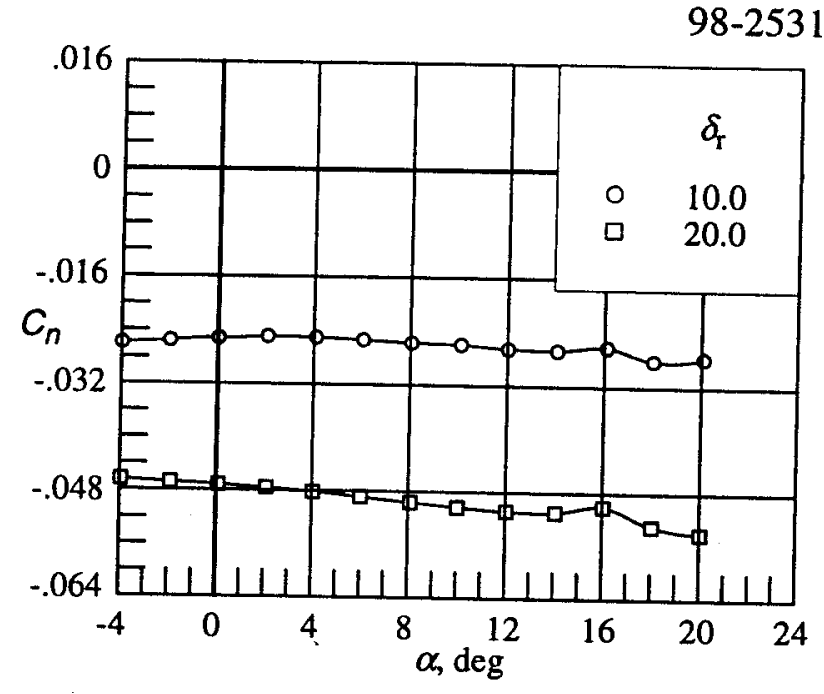

Figure 17. Effect of rudder deflection at low speed 